\title{
Behavior of 2, 9-Dimethyl-1, 10-phenanthroline Additive in Electroless Copper Plating
}

\author{
Masahiro OITA* and Katsuhiko HONJO** \\ 無電解銅めっきにおける 2,9 - ジメチルー1, 10-フェナントロリン添加剤の挙動 \\ 老田昌 弘*, 本 城 克 彦**
}

Key Words : Electroless Copper Plating, Phenanthroline, Copper Deposition, Colorimetry, Additive

\section{Introduction}

Electroless copper plating is also referred to as chemical copper plating. As its name implies a copper complex is chemically or autocatalytically reduced to copper on a catalytic surface. In general, a copper deposit obtained in this plating has poor physical properties compared with one obtained in copper electroplating. For the improvement of properties of electroless copper, some additives have been proposed ${ }^{1), 2)}$. Among them , 2,9-dimethyl-1,10-phenanthroline (2,9dmph), which is a $\mathrm{Cu}(\mathrm{I})$ chelating ligand and often used for a reagent for the spectrophotometric analysis ${ }^{3)}$ of copper is known to give rise to a ductile copper deposit ${ }^{1)}$. Since little is known about the working mechanism of 2,9-dmph in this plating, studies on it have been done. Our previous publication ${ }^{4}$ could give considerable insight into its working mechanism. Whether 2, 9-dmph was reproduced in the bath, however, was a matter for argument. As for the behavior of $2,9-\mathrm{dmph}$, it is intriguing to note that its effects such as giving the deposit good ductility last long, although it is added in a small amount in the bath. From this fact, it can be assumed that there is the possibility of reproduction of 2,9 dmph in the bath. Such being the case, a further study has been made for confirming this view.

\section{Experimental}

Bath.-The bath composition was $0.030 \mathrm{~mol} / \mathrm{L}$ $\mathrm{CuSO}_{4} 5 \mathrm{H}_{2} \mathrm{O}, 0.036 \mathrm{~mol} / \mathrm{L}$ EDTA, $0.068 \mathrm{~mol} / \mathrm{L}$

* Tech. Support Center, Matsushita Electronics Co., Ltd. (1, Koutariyake-machi, Nagaokakyo-shi, Kyoto 617)

松下電子工業(俐) 技術助成センター

** Video Division, Matsushita Electric Ind. Co., Ltd. (1-15, Shosei-cho, Kadoma-shi, Osaka 571)

松下電器産業(俕 ビデオ事業部
HCHO, and $50 \mathrm{mg} / \mathrm{L} \mathrm{2,9-dmph} \mathrm{as} \mathrm{an} \mathrm{additive.}$ The bath was adjusted to $\mathrm{pH} 12.0$ prior to plating. The temperature of the bath was maintained at 70 ${ }^{\circ} \mathrm{C}$ in the process of plating.

Colorimetry.-Collecting $5 \mathrm{~mL}$ of the bath in a test tube, a copper wire $0.6 \mathrm{~mm}$ in diameter and $0.8 \mathrm{~m}$ in length was soaked in the bath and plated for a given period of time. After the wire was withdrawn from the bath, $7 \mathrm{~mL}$ isoamyl alcohol preheated at $70^{\circ} \mathrm{C}$ was added to the bath to extract the colored 2, 9-dmph-Cu(I) complex formed in the bath by use of a separatory funnel. The extract was made up to $10 \mathrm{~mL}$ with ethyl alcohol. For the colorimetric determination of the $\mathrm{Cu}(\mathrm{I})$ complex, the absorption spectra of the extract were measured with a Shimadzu Sp20 spectrophotometer by use of isoamyl alcohol as the reference solution.

A calibration curve was obtained by reference to Gahler's work ${ }^{3 \text {. }}$. The curve obeyed Beer's law in the range of $\mathrm{Cu}$ concentration of 0.005 to 0.05 $\mathrm{mg} / 10 \mathrm{~mL}$.

\section{Results and Discussion}

$\mathrm{Cu}$ (I) complex of 2,9-dmph.- Fig. 1 shows the comparison of the absorption curves of extracts obtained in the bath before and after electroless plating. Curve a shows the absorption spectra of extract obtained in the bath after $3 \mathrm{~min}$ of plating. The wavelength of maximum absorption at 450

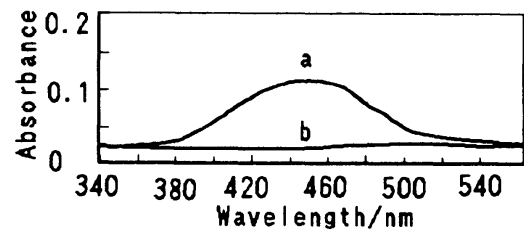

Fig. 1 Absorption curves of 2,9-dmph-Cu (I) complex extracted from the bath described in Experimental. a : after plating for $3 \mathrm{~min}, \mathrm{~b}$ : before plating. 
$\mathrm{nm}^{4)}$ is almost identical with the $454 \mathrm{~nm}$ reported by McCurdy, Jr. and Smith ${ }^{5)}$ for the cuprous complex of 2,9-dmph. This accounts for the forming of 2,9-dmph-Cu(I) complex in the bath as a result of electroless plating. Absorbance at $450 \mathrm{~nm}$ and a calibration curve prepared in advance allow us to estimate the amount of the $\mathrm{Cu}$ (I) complex formed in the bath. In contrast, since absorption curve $b$ obtained from the extract of the bath before plating did not exhibit any measurable effect on the intensity of absorption spectra, little of the $\mathrm{Cu}$ (I) complex was found to be formed. From these data and previous paper ${ }^{4}$, it is elucidated that 2,9-dmph is adsorbed on the copper wire to be plated and that reaction between the adsorbed 2,9-dmph and the copper wire occurs to form the 2,9-dmph-Cu(I) complex and that the resulting $\mathrm{Cu}(\mathrm{I})$ complex dissolves satisfactorily in the bath, rendering the color of the bath greenish.

Behavior of 2, 9-dmph additive.-From the determination of the $\mathrm{Cu}(\mathrm{I})$ complex, the ratio of 2,9$\mathrm{dmph}$ forming the $\mathrm{Cu}$ (I) complex to a total amount of 2,9-dmph added in the bath was observed as a function of plating time. The data obtained are shown in Fig. 2. The ratio increased gradually with plating time and a plateau was reached in $10-15 \mathrm{~min}$. This plateau indicates a steady state where approximately $30 \%$ of 2,9 -dmph added in the bath formed the $\mathrm{Cu}(\mathrm{I})$ complex. Paying attention to developments of the 2, 9-dmph$\mathrm{Cu}(\mathrm{I})$ complex thus formed in the bath is interesting. After the copper wire was plated for $3 \mathrm{~min}$ and then taken out of the bath, the bath was allowed to stand for given periods of time. The ratio of 2, 9-dmph forming the $\mathrm{Cu}(\mathrm{I})$ complex to a total amount of 2, 9-dmph as a function of standing time is shown in Fig. 3. The ratio decreased gradually with standing time and after $7 \mathrm{~min}$ of standing, the $\mathrm{Cu}(\mathrm{I})$ complex present in the bath almost disappeared. In the course of standing, the bath had a color varying from green to blue to the naked eye too. This means that the $\mathrm{Cu}(\mathrm{I})$ complex can be no longer formed in the bath in the absence of the wire to be plated and that reaction between the $\mathrm{Cu}$ (I) complex formed so far and free EDTA present in the bath occurs, yielding blue $\mathrm{CuY}^{2-}$ and colorless 2,9-dmph. From these results and previous paper ${ }^{4}$ as well, one can conclude that the working of 2, 9-dmph is the following steps of 1) adsoption of 2,9-dmph on the copper electrode to be plated, 2) formation of the 2, 9-dmph-Cu (I) complex on the copper electrode, 3) transference of the $\mathrm{Cu}(\mathrm{I})$ complex in the solution, and 4) reproduction of 2,9-dmph in the bath. With the reproduction step included, it is easily understood that the working of 2,9-dmph

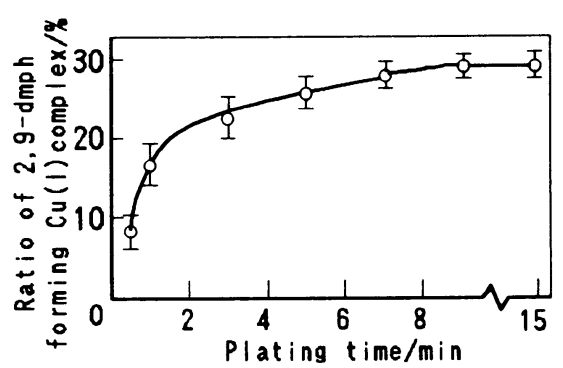

Fig. 2 Effect of plating time on $\mathrm{Cu}$ ( I ) complex formed in the bath described in Experimental.

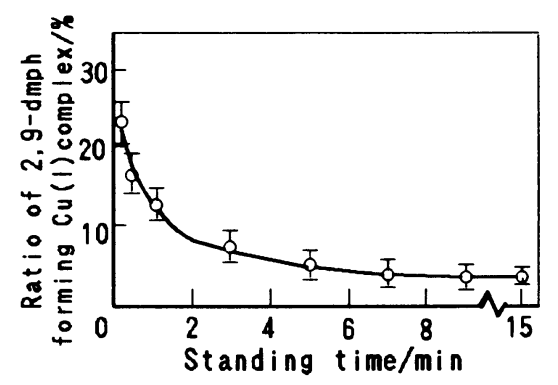

Fig. 3 Effect of standing time on $\mathrm{Cu}$ ( I ) complex amount in the bath after $3 \mathrm{~min}$ of plating. bath : described in Experimental

is constantly repeated during the course of plating. This is responsible for prevention of depletion of 2,9-dmph in the bath and for its continuing effectiveness of yielding ductile copper.

\section{Conclusion}

(1) The additive 2,9-dmph was reproduced constantly in the plating bath and this was responsible for the continuing effect of yielding ductile deposits.

(2) The amount of the 2, 9-dmph-Cu(I) complex formed in the bath increased with plating time ; at a steady state about $30 \%$ of $2,9-\mathrm{dmph}$ present in the bath formed the $\mathrm{Cu}(\mathrm{I})$ complex.

(3) Little of the 2,9-dmph-Cu (I) complex was formed before plating.

(Received February 14, 1994 ; Accepted March 28, 1994)

\section{References}

1) H. Hirohata, M. Oita and K. Honjo ; U. S. Patent, 4, 002, 786 (1977)

2 ) M. Saito and H. Honma ; Kinzoku Hyomen Gijutsu, 29, 190 (1978)

3 ) A. R. Gahler ; Anal. Chem., 26, 577 (1954)

4) M. Oita and K. Honjo; Hyomen Gijutsu, 42, 833 (1991)

5 ) W. H. McCurdy, Jr. and G. F. Smith ; International Congress on Anal. Chem., 77, 846 (1952) 